\title{
INTERVENÇÃO COM PAIS DE CRIANÇAS DEFICIENTES AUDITIVAS: ELABORAÇÃO E AVALIAÇÃO DE UM PROGRAMA DE ORIENTAÇÃO NÃO PRESENCIAL
}

\author{
INTERVENTION WITH PARENTS OF HEARING IMPAIRED CHILDREN: ELABORATION AND \\ EVALUATION OF AN ORIENTATION PROGRAM NOT REQUIRING ATTENDANCE
}

\author{
Telma Flores Genaro MOTTI ${ }^{1}$ \\ Maria Benedita Lima PARDO²
}

RESUMO: as orientações aos pais favorecem a aceitação da deficiência auditiva e esclarecem possibilidades e condutas que viabilizam o desenvolvimento da criança. Devem ser cuidadosas, a fim de evitar insegurança, ansiedade, expectativas irreais ou reações inadequadas dos pais. Essas orientações são oferecidas no diagnóstico e no acompanhamento, mas as restrições de tempo e financeiras são dificuldades dos pais para o comparecimento freqüente a programas que forneçam um suporte contínuo. A proposta deste trabalho foi elaborar e avaliar um programa de orientação não presencial para pais de crianças com deficiência auditiva severa e profunda, de dois a seis anos de idade. O programa, estruturado em quatro unidades, foi aplicado a 30 pais atendidos no Hospital de Reabilitação de Anomalias Craniofaciais da USP, em Bauru/SP. As unidades foram formuladas com base nas orientações que os especialistas de diferentes áreas transmitem durante o diagnóstico da deficiência auditiva e nas dificuldades e interesses dos pais, identificando-se o conhecimento sobre as avaliações e acompanhamentos, opiniões sobre desempenho e necessidades da criança, deles próprios e das famílias. Para avaliação do programa foram analisadas as respostas dos pais aos questionários das unidades e às entrevistas finais. As análises revelaram que o programa forneceu aos pais, como eles desejavam, informações claras e sugestões de atividades que pudessem ser adequadas ao contexto familiar e colaborassem para o desenvolvimento da criança. Alguns pais encontraram dificuldade em se expressar por escrito e realizar algumas atividades, mas nas entrevistas, foi verificado que tal fato não inviabilizou o entendimento e a participação no programa.

PALAVRAS-CHAVE: educação especial; deficiência auditiva; surdez; orientação de pais; programa de orientação.

\begin{abstract}
: orientation of parents enables them to accept their child's deafness and it also helps them understand treatment options that will enable their child to develop favorably. Orientation should be carefully presented in order to avoid insecurity, anxiety, unreal expectations or inadequate reactions on the part of the parents. Orientation is offered at the time of diagnosis and during follow-up, though the parents may present financial difficulties and little time to enroll in ongoing support programs. The aim of this study was to develop and evaluate an orientation program for parents of children between two and six years with severe and profound deafness who were unable to attend the treatment center. The program was structured in four units and was applied with 30 parents who initially were enrolled at the University of São Paulo Hospital de Reabilitação de Anomalias Craniofaciais, in Bauru/SP. The units were prepared based on content that specialists from various fields divulge during diagnosis of hearing impairments, considering the interests and difficulties parents express. Their level of understanding was identified as to assessment, follow-up, opinions about achievement as well as the child's needs, their own and their family's needs. In order to evaluate the program, parents' answers to a questionnaire on each unit were analyzed, and final interviews were conducted. The analysis revealed that the program offered clear information and suggestions of activities that were adequate to the family context,
\end{abstract}

\footnotetext{
${ }^{1}$ Doutora em Educação Especial, Hospital de Reabilitação de Anomalias Craniofaciais da Universidade de São Paulo, Assistente Técnica de Direção. telmotti@centrinho.usp.br

${ }^{2}$ Departamento de Psicologia da Universidade Federal de Sergipe, Professor Adjunto, Núcleo de Pós-graduação em Psicologia Social.pardomb1@hotmail.com
} 
and that the program contributed to the children's development. Some parents had difficulty expressing themselves in writing and in developing some of the activities, nevertheless, this did not undermine their understanding and their participation in the program.

KEYWORDS: Special Education; Hearing Impairment; Orientation for Parents; Orientation Program.

\section{INTRODUÇÃo}

A orientação aos pais é fundamental para a aceitação da deficiência auditiva e viabilização de situações favoráveis ao desenvolvimento da criança. O período durante o diagnóstico, e imediatamente após, traz oportunidades aos profissionais envolvidos nas avaliações, para esclarecerem as possibilidades da criança e as condutas adequadas a serem seguidas, visando o desenvolvimento esperado pelos pais.

As orientações dos profissionais devem ser cuidadosas e claras, a fim de evitar insegurança e ansiedade, expectativas irreais ou reações inadequadas dos pais, que podem ser mais prejudiciais do que a deficiência em si. Ouvirem os pais, permitirem que expressem seus pensamentos, serem compreensivos, oferecerem respostas diretas e informações objetivas, são algumas das recomendações aos profissionais (HOLZHEIM et al., 1997).

Os profissionais ajudam os pais a elaborarem expectativas adequadas sobre o desenvolvimento da criança com deficiência auditiva, ao transmitirem informações realistas quanto ao benefício do Aparelho de Amplificação Sonora Individual (AASI), mas devem ser sensíveis aos sentimentos e preocupações deles, que incluem a aparência e aceitação social da criança, quando a mesma usa o aparelho (SJOBLAD et al., 2001).

É importante que as necessidades de informação dos pais sejam identificadas, pois os sentimentos de confusão e incompetência que surgem como reações ao diagnóstico tendem a diminuir com o tempo, à medida que eles recebem as informações que desejam sobre as influências da deficiência no desenvolvimento da criança, amenizando seu estresse emocional (COLNAGO, 2000).

Os pais podem lidar melhor com a situação ao aceitarem a deficiência auditiva e suas prioridades se modificam do momento do diagnóstico há após alguns meses. Harrisson e Roush (2001) verificaram que pais de crianças menores de cinco anos com perdas auditivas severa e profunda, no diagnóstico, queriam saber a causa da deficiência, lidar com os aspectos emocionais e aprender sobre audição e fala. Depois de alguns meses esses pais priorizaram aprender sobre audição e fala, seguido de informações sobre o Implante Coclear e opções de comunicação, indicando que os temas relacionados à comunicação tornaram-se mais relevantes.

Desse modo, atendendo aos interesses dos pais e somando experiências de especialistas de diferentes áreas, é possível proporcionar uma intervenção centrada na família, inclusiva e ecológica, envolvendo os familiares na adaptação e uso da amplificação e na reabilitação da criança deficiente auditiva. 
Atitudes realistas dos pais, assim como motivação, são decisivas para o sucesso da intervenção. A constante interação, estimulação e exploração de eventos diários favorecem trocas comunicativas, treinamento das habilidades auditivas e desenvolvimento da linguagem da criança. Ainda que lentamente, ao perceberem os resultados positivos, os pais podem encontrar satisfação e motivação para a continuidade dos esforços.

As crianças com deficiência auditiva têm necessidades e desejos como as ouvintes, embora necessitem de cuidados especiais. Seus pais podem confundir os problemas de desenvolvimento com os da deficiência auditiva, resultando em disciplina inadequada ou baixa expectativa em relação à criança e seu comportamento. Podem mimá-la e superprotegê-la, impedindo o desenvolvimento social (BEVILACQUA; FORMIGONI, 1997).

Para Colnago (2000) a tarefa de favorecer o desenvolvimento físico, afetivo e social da criança é desafiante e gratificante, apesar de gerar insegurança aos pais frente à sua competência. Tal insegurança pode ser intensificada com a deficiência. Entretanto, a ajuda profissional pode fazer com que se sintam seguros, acreditem nas próprias capacidades para lidar com a criança, superem os sentimentos de choque e culpa e aceitem a deficiência auditiva do filho e o uso do AASI.

Existem, ainda, no caso da surdez, possibilidades de reabilitação oralista, gestual, bilíngue, uso de AASI ou de Implante Coclear, e os pais somam suas concepções às informações, orientações e atitudes dos profissionais durante o diagnóstico, bem como à oferta e acesso aos recursos da comunidade para a tomada de decisões que influenciam o futuro da criança. Portanto, é necessário que os pais conheçam as abordagens e opções metodológicas para a criança se comunicar e ser educada, e que os profissionais considerem as condições culturais e linguísticas singulares da família no planejamento das orientações e programas educacionais (HARRISON; LODI; MOURA, 1997; STELLING, 1999; CHEROW; DICKMAN; EPSTEIN, 1999; MOTTI; PARDO, 2003).

As orientações aos pais podem abordar aspectos auditivos, de fala e linguagem, para que compreendam o problema do filho e possam estabelecer a forma de tratá-lo e promover seu desenvolvimento. Devem informar sobre uso e cuidados com o AASI, seu funcionamento, a troca dos acessórios e a manipulação dos controles, assim como as possibilidades e abordagens comunicativas, educacionais e os direitos da criança, para que os pais busquem as alternativas mais condizentes para ela e a família.

Além dessas orientações oferecidas por profissionais no momento do diagnóstico e no decorrer do acompanhamento de crianças com deficiências, programas de orientação podem fornecer um suporte contínuo a pais e familiares.

Um programa de orientação pode associar conhecimentos sobre o funcionamento familiar, estratégias efetivas de intervenção, integrar diferentes abordagens e terapêuticas baseadas em necessidades identificadas, considerar as 
dificuldades vivenciadas, as relações interpessoais, os problemas de desenvolvimento, as possibilidades de estimulação e formas mais adequadas de cuidar da criança, visando à melhoria do desenvolvimento pessoal, o crescimento das relações familiares e resgatando o papel da família no desenvolvimento do indivíduo com necessidade especial (COLNAGO, 2000; SIGOLO, 2002).

Em trabalho anterior, pais de 50 crianças com deficiência auditiva foram entrevistados durante o diagnóstico e após três meses, sendo analisado como retinham e aplicavam as orientações recebidas nos atendimentos. Estes atendimentos também foram descritos detalhadamente, mediante entrevistas com profissionais que os realizavam. Foram identificadas mudanças de condutas dos pais relacionadas à comunicação com a criança, ao acompanhamento terapêutico e escolar e ao uso do AASI. Embora as informações e orientações tenham sido compreendidas pelos pais, as condutas que dependiam de recursos externos, tais como a fonoterapia, não eram as mais seguidas por serem inacessíveis à maioria das famílias. Apesar disso, os pais relataram melhora na comunicação e comportamento da criança, ou seja, estavam obtendo bons resultados ao atuarem eles próprios com os filhos. Tais resultados mostram a importância de orientações compreensíveis aos pais e, principalmente, aos contextos sociais, econômicos e culturais nos quais estão inseridos (MOTTI, 2000).

A restrição de tempo e de recursos financeiros são dificuldades das famílias que atrapalham o envolvimento dos pais em programas que solicitam presença, atividades e contatos frequentes. Mas são esses contatos que permitem acompanhar o uso do AASI, esclarecer dúvidas, trabalhar ansiedades e inseguranças, trocar experiências, incentivar as atividades que estimulem a linguagem, bem como desenvolver nos pais a percepção para que observem a evolução da criança, de forma que se conscientizem de sua capacidade e competência na lida com os filhos. Assim, alternativas devem ser buscadas para que as famílias tenham acesso às informações e as revertam em benefício do desenvolvimento global da criança surda e da sua própria dinâmica cotidiana.

Um programa educativo para os pais de crianças deficientes auditivas pode sistematizar informações e servir de apoio em resposta aos questionamentos, tornando-se um recurso útil para todas as famílias, especialmente aquelas com dificuldade de acesso aos profissionais especializados. Pode ainda reverter em melhor qualidade de vida deles próprios e da criança deficiente auditiva, atendendo a uma proposta de intervenção centrada na família e valorizando os pais enquanto mediadores do desenvolvimento do filho.

Diante da escassez de propostas de orientação a famílias de crianças deficientes auditivas foi elaborado, aplicado e avaliado um programa de orientação não presencial dirigido aos pais de crianças com perdas severa e/ou profunda, fundamentado nas informações dos especialistas de diferentes áreas, bem como nos interesses e necessidades das famílias. 


\section{MÉTodo}

O projeto da pesquisa foi submetido e aprovado pelo Comitê de Ética em Pesquisa do HRAC/USP os pais participantes assinaram o TCLE.

A pesquisa teve por princípio a interdisciplinaridade e o paradigma ecológico, considerando a importância da interação e das influências mútuas das características individuais das crianças e dos pais, do ambiente familiar e dos ambientes sociais mais amplos (BRONFENBRENNER, 1996; SIGOLO, 2002). A abordagem qualitativa foi utilizada para a análise dos dados (MINAYO, 1999). A atuação direta com os sujeitos, a elaboração do material escrito para atender às necessidades dos pais e a solicitação para que respondessem questões e executassem atividades caracterizou o aspecto clínico do trabalho (TURATO, 2003).

\subsection{ElaboraÇão do PROGRAMA DE ORIENTAÇÃo}

O programa, constituído de quatro unidades compostas de conteúdos teóricos básicos e propostas de atividades práticas foi elaborado, aplicado e avaliado no Hospital de Reabilitação de Anomalias Craniofaciais da Universidade de São Paulo (HRAC/USP).

Inicialmente foram definidos os temas a serem abordados, utilizando-se como fontes de informações, além dos pais das crianças com deficiência auditiva, um estudo anterior realizado por Motti (2000), para o qual foram entrevistados 36 profissionais envolvidos na rotina de diagnóstico da deficiência auditiva do Centro de Distúrbios da Audição, Linguagem e Visão (Cedalvi/HRAC/USP). Segundo esses profissionais, após os atendimentos os pais deveriam estar cientes das avaliações realizadas para o diagnóstico, seus resultados, possíveis causas da deficiência auditiva e recursos para reabilitação da criança.

Também foram levantadas por meio de entrevistas junto a pais ou responsáveis de 30 crianças que participaram do programa de orientação, as dificuldades enfrentadas pelas crianças, por eles e pelos familiares. O comportamento foi identificado como a maior dificuldade das crianças $(56,7 \%)$, seguido da comunicação $(36,7 \%)$. Para os pais, a maior dificuldade citada foi a comunicação (43,3\%), seguida do comportamento da criança (36,7\%) assim como para os familiares, que indicaram a comunicação com a criança $(33,3 \%)$ e a seguir o comportamento $(23,3 \%)$. Outros tipos de dificuldades foram relatados incluindo problemas físicos da criança como coordenação motora, questões emocionais dos pais como sentimento de culpa pela deficiência e atitudes deles como impaciência.

Quanto às informações que gostariam de receber, a maioria das respostas $(56,7 \%)$ dos pais indicou a aprendizagem da criança, como estimulá-la para a comunicação, esclarecimentos sobre terapias e abordagens com sinais ou oralização, sobre a escola, sendo que em quatro casos houve manifestação por materiais escritos para eles ou para os profissionais que tratavam da criança. 
As respostas também indicaram interesse dos pais sobre a deficiência auditiva $(36,7 \%)$ quanto à causa e cuidados para não piorar a perda; sobre recursos de amplificação sonora (30,0\%) abrangendo cuidados, resultados do AASI em relação à fala e indicação de implante coclear e, comportamento $(20,0 \%)$, incluindo informações sobre colocar limites, lidar com a teimosia, a birra e a superproteção. Outros tipos de informações referidos em $6,7 \%$ das respostas mencionavam direitos e benefícios.

A análise das respostas dos pais na entrevista inicial quanto às informações que gostariam de receber orientou a organização dos temas em quatro unidades. As informações dos profissionais sobre as orientações aos pais foram inseridas nas unidades e complementadas com dados da literatura, utilizando-se vocabulário que favorecesse o entendimento dos conteúdos.

As unidades elaboradas eram independentes e intercalavam conteúdo teórico, sugestões de atividades que os pais poderiam desenvolver com seus filhos e questionários com perguntas sobre os temas tratados, para avaliar o programa de orientação. No final de cada unidade constavam perguntas enfocando a compreensão do pai ou responsável sobre o material recebido, suas dificuldades e sugestões.

Ao concluir a elaboração de cada unidade foi solicitado que profissionais que atuavam no atendimento de pais, representados por seis fonoaudiólogas, duas psicólogas, uma pedagoga e uma assistente social, avaliassem a adequação dos assuntos abordados aos interesses que os mesmos rotineiramente manifestavam e sugerissem, quando necessário, a substituição de termos visando facilitar a compreensão.

O Quadro 1 sintetiza os conteúdos das unidades que constaram do programa de orientação elaborado.

\begin{tabular}{|c|l|}
\hline Unidade & \multicolumn{1}{c|}{ Conteúdo } \\
\hline 1 & Assuntos relacionados à deficiência auditiva, ao diagnóstico e à adaptação do AASI. \\
\hline 2 & $\begin{array}{l}\text { A reação da família frente ao diagnóstico e sua influência no desenvolvimento linguístico, } \\
\text { cognitivo e psicossocial da criança, por meio da exploração das atividades diárias e domésticas } \\
\text { para estimular a comunicação. }\end{array}$ \\
\hline 3 & Comportamento da criança \\
\hline 4 & $\begin{array}{l}\text { Informações sobre os apoios previstos na legislação e os recursos existentes que podem ser } \\
\text { acionados para melhorar a qualidade de vida das crianças e das famílias. }\end{array}$ \\
\hline
\end{tabular}

Quadro 1 - Unidades do programa de orientação não presencial para pais de crianças com deficiência auditiva severa e profunda e respectivos conteúdos

\subsection{Participantes}

Participaram do programa de orientação pais ou responsáveis por 30 crianças, sendo 18 meninos e 12 meninas, entre dois e seis anos de idade, com 
perda auditiva neurossensorial bilateral severa a profunda, que haviam sido diagnosticadas, adaptadas com AASI e ainda se encontravam em atendimento no Cedalvi/HRAC/USP.

Essas crianças e suas famílias procediam de 11 diferentes estados brasileiros, sendo 23,3\% de São Paulo. As idades dos pais das crianças variavam de 21 a 43 anos e das mães de 20 a 42 anos. A escolaridade dos pais e das mães, que poderia interferir no entendimento aos materiais escritos, distribuiu-se entre ensino fundamental incompleto $(35,0 \%)$, ensino médio incompleto $(23,3 \%)$, ensino superior incompleto $(20,0 \%)$ e ensino superior completo $(6,7 \%)$.

\subsection{Procedimentos para coleta e anÁlise dos dados}

A primeira unidade do programa foi enviada pelo correio, para cada pai ou responsável e no recebimento do questionário referente à unidade, foi encaminhada a unidade seguinte, e assim sucessivamente. Após o recebimento do questionário da quarta e última unidade, uma entrevista final foi programada, retomando algumas questões sobre as condutas adotadas com a criança, os acompanhamentos terapêutico e educacional, como os pais avaliavam esses acompanhamentos, além de algumas questões gerais a respeito do programa.

Ao longo das quatro unidades foram inseridas questões para que os pais respondessem, apontando suas dificuldades e sugestões, bem como solicitações de relatos e exemplos das atividades propostas. Essas respostas dos pais, bem como as entrevistas finais realizadas, foram analisadas quanto ao conteúdo (BARDIN, 2004) e possibilitaram avaliar o programa quanto à compreensão do conteúdo e sua receptividade.

A seguir são apresentados as unidades e o desempenho dos pais, de acordo com as respostas aos questionários e a execução das atividades.

\section{Resultados E Discussão}

\section{UNIDADE 1}

A unidade 1 abordou informações relacionadas à deficiência auditiva, ao processo de diagnóstico e a intervenção imediata com amplificação sonora, fonoterapia e escola, tratando temas específicos ao AASI como cuidados e manutenção. Após a apresentação de cada tópico, foram inseridas questões para os pais responderem, relacionando os assuntos tratados às características do filho. No final, 96,7\% (29) dos pais responderam que haviam entendido todas as informações da unidade e 96,7\% (29) negaram dificuldades em responder ao questionário, tendo um único pai justificado sua dificuldade por conviver pouco com a filha. 


\section{UNIDADE 2}

A unidade 2 foi elaborada pensando no processo de aceitação da deficiência auditiva, tendo em vista a reação dos pais ao diagnóstico e considerando a influência do ambiente familiar para o desenvolvimento linguístico, cognitivo e psicossocial das crianças. Foi abordado desde o impacto da identificação da perda auditiva, o relacionamento interpessoal, até atividades que poderiam ser exploradas pelos familiares.

Logo na mensagem inicial foi enfatizada a reação ao diagnóstico da perda auditiva como o medo de algo desconhecido, sendo destacada a importância dos pais como primeiros professores da criança e do ambiente doméstico onde acontece o aprendizado das relações sociais. Procurou-se deixar claro que as dificuldades, financeiras ou não, eram comuns a todas as famílias, objetivando-se, com isso, que os pais entendessem suas responsabilidades, mas se sentissem seguros para atender às sugestões do programa, dentro do que lhes fosse possível.

Nesta unidade foram introduzidas algumas atividades práticas de comunicação, envolvendo palavras e modos como os pais poderiam ensinar seus filhos nas situações diárias. Após expor sobre a função e o uso de substantivos, verbos e adjetivos, solicitou-se que eles observassem e selecionassem exemplos de nomes e verbos mais utilizados e os explorassem com o filho, por meio de figuras ou desenhos. As figuras 1 e 2 trazem exemplos de atividades desenvolvidas nesta unidade.

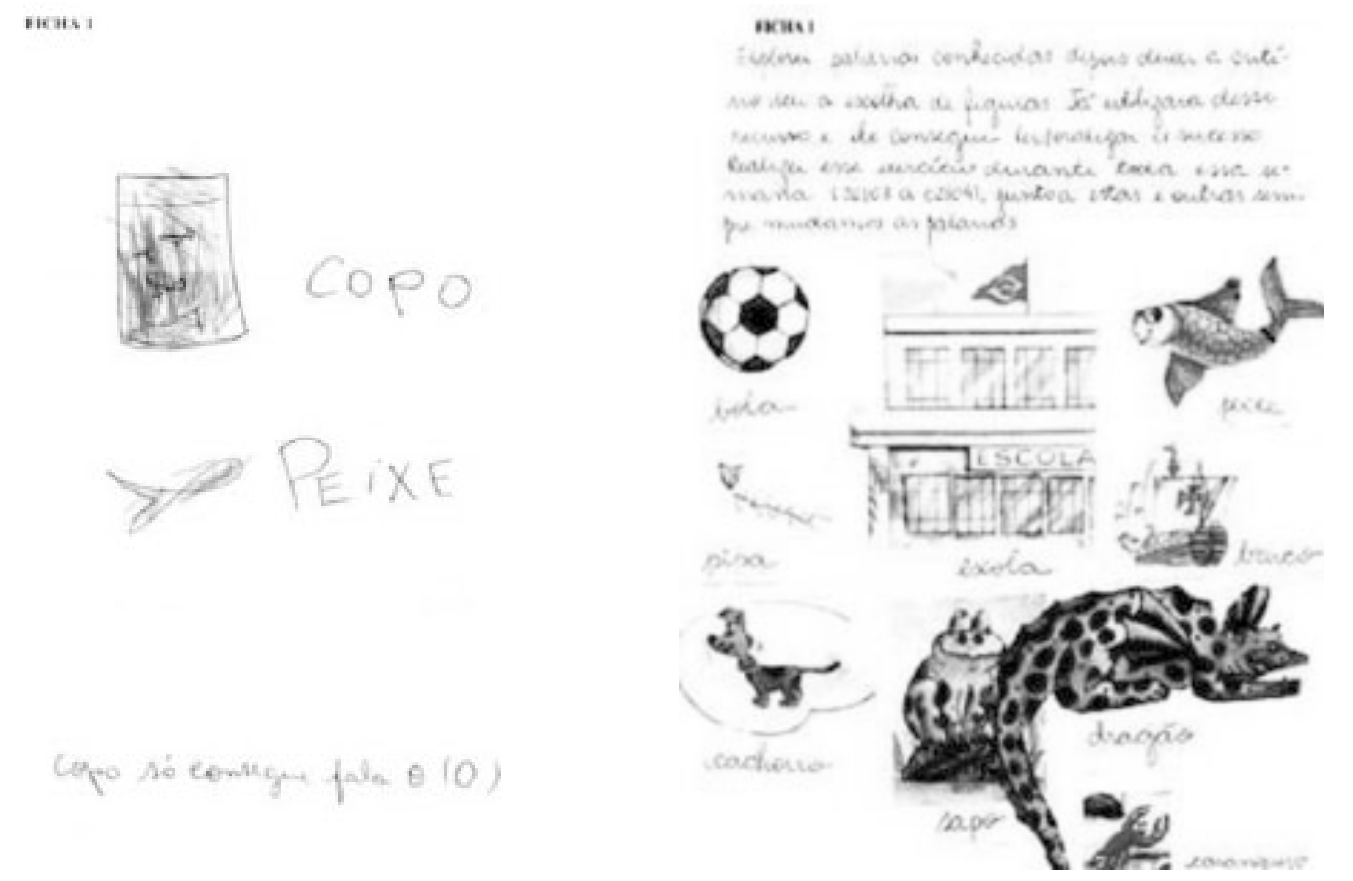

Figura 1 - Exemplo de ficha com atividade desenvolvida pela criança com auxílio dos pais, explorando substantivos. 



Figura 2 - Exemplo de ficha com atividade desenvolvida pela criança com auxílio dos pais, explorando verbos.

Para que os pais pudessem trabalhar o conceito de adjetivo com a criança, sugeriu-se, por exemplo, que utilizassem pedaços de fruta e peças de roupa de diferentes tamanhos (grande e pequeno) ou explorassem temperaturas diferentes com água e leite (quente e frio).

Noções de tempo, números e quantidade, igual e diferente, que os pais poderiam ensinar à medida que introduzissem novas palavras, também foram abordadas. Foi solicitado que os pais relatassem uma atividade praticada com a criança, para cada um desses conceitos, envolvendo número e quantidade e exemplos de situações, atividades ou brincadeiras com as noções de igual e diferente. Finalizando o tópico sobre palavras e conceitos, foram levantadas as dúvidas dos pais quanto a ensinar as crianças.

A unidade 2 teve sequência com informações para os pais aproveitarem as brincadeiras, utilizando objetos, fotografias, figuras e estórias, para ensinar conceitos abstratos, como passado e futuro. Como atividade prática, apesar das limitações de comunicação, foi proposto que os pais escolhessem uma situação e, com a ajuda da criança, montassem um livro com figuras ou desenhos e, ainda, depois disso, contassem uma estória. 
$\mathrm{Na}$ avaliação desta unidade, $86,7 \%$ (26) das respostas manifestavam entendimento dos pais às informações e 50,0\% (15) negavam dificuldades. Em 46,7\% (14) das respostas indicativas de dificuldade, duas referiam as atividades de contar estória e elaborar as fichas com palavras e verbos e outras três ao comportamento da criança:

“... ela ainda não dá muita atenção” (P28)

"... tem apenas 4 anos, tem pouco tempo que está com o aparelho, está sempre desatenta" (P12)

"Só alguns testes com a criança, pois ela ainda é muito nova" (P10)

As justificativas mais importantes para avaliação da unidade 2 do programa de orientação foram sete respostas que traziam dificuldades dos pais em relação ao entendimento das questões propostas ou em expressar sentimentos e opiniões próprias. Alguns exemplos dessas respostas remetem à aceitação da deficiência, à expectativa dos pais em atender ao solicitado e à tentativa deles em superarem as dificuldades:

"É um pouco difícil falar da surdez da minha filha" (P15)

"... algumas perguntas ficaram dificeis, pois não sabemos se o que respondemos está de acordo com o que queria saber" (P03)

"As questões que o W. tinha que ajudar foi difícil, porque ele não entende só com a gente falando, usamos também os sinais" (P29)

\section{UNIDADE 3}

A Unidade 3 tratou dos comportamentos e da comunicação da criança deficiente auditiva e de como lidar com as situações correlacionadas. Para sua estruturação foram consideradas as necessidades e interesses dos pais a respeito do comportamento da criança. A proposta era que os pais se dispusessem a entender os sentimentos e as emoções que a criança experimenta no processo de se tornar independente, os quais desencadeiam comportamentos dentro e fora da família, aceitáveis ou não. Pais e adultos com quem a criança convive participam desse processo ensinando, reconhecendo e incentivando seus esforços e evitando o uso de comportamentos, que podem ser considerados inadequados, para chamar atenção. A criança aos poucos incorpora os pré-requisitos para aceitação social, aprendendo a respeitar e a negociar.

Foram incluídas questões no início da unidade, cujas respostas exigiam que os pais atentassem para a qualidade dos relacionamentos sociais da criança, seus amigos, suas atitudes para obter atenção das pessoas, como ela partilhava brinquedos e como poderia ser ampliado seu círculo de amigos. Também se questionou a opinião dos pais sobre a qualidade e melhoria do relacionamento da criança com outros adultos.

Como atividade foi proposto aos pais montarem uma caixa de brinquedos com sucatas e materiais disponíveis e brincarem com a criança. O calendário foi 
introduzido para ser aplicado à rotina diária, associando a participação da criança em pequenos afazeres, sugerindo-se aos pais que organizassem um quadro com os dias da semana e os moradores da casa, dividindo algumas tarefas.

O assunto seguinte tratado na unidade referia-se ao comportamento da criança e foi solicitado que os pais citassem três comportamentos que os agradava. Após essa percepção positiva foi solicitado que identificassem um comportamento que não os agradava e o motivo pelo qual ela apresentava este comportamento, uma vez que assim, observando-a, poderiam conhecê-la melhor. Em seguida perguntou-se se eles sabiam como prevenir tal comportamento.

Depois desse exercício sobre comportamentos da criança, solicitou-se um exemplo de regra em casa e se a mesma era obedecida, e que relatassem uma desavença, a reação que tiveram à mesma e como eles avaliavam essa reação, se poderia ter sido diferente.

A fim de que os pais percebessem que eram modelos para os filhos foi solicitado que apontassem um comportamento que a criança imitava, outro que gostariam que fosse diferente e se sabiam o que fazer para modificar esse comportamento.

A importância dos pais reconhecerem as habilidades dos filhos, assim como de partilharem deveres e ensinarem responsabilidades, foi abordada, solicitando-se que indicassem uma tarefa da casa que a criança era capaz de fazer bem.

Após expor na unidade a conveniência da criança manifestar seus sentimentos negativos de maneira aceitável, os pais foram questionados se aprovavam como os filhos expressavam tais sentimentos e como poderiam ajudálos a melhorar esses comportamentos. Também foi solicitado que identificassem um medo da criança e como poderiam ajudá-la a superá-lo. Enfim, duas questões abordaram as atitudes dos pais, como eles poderiam contribuir para ajudar no aprendizado e comportamento do filho às refeições e na hora de dormir.

Quanto ao entendimento das informações desta unidade 3, mais extensa, complexa e com um maior número de atividades do que as anteriores, 90,0\% (27) das respostas dos pais foram afirmativas. Os pais negaram dificuldades em $66,7 \%$ (20) das respostas e justificaram as afirmativas (7) devido ao não entendimento ou a não execução das atividades pela criança, ou a dificuldade deles se expressarem, como os exemplos:

\footnotetext{
"Apesar de entender as perguntas ficou difícil de expressar-me por escrito" (P26)

"... tenho dificuldade para as tarefas é bastante complicado e não tenho muito tempo" (P15)

"a do quadro de tarefas, não de relatar, mas de explicar pro meu filho, que hoje é segunda amanhã é terça... Mas foi bom que ele começou a entender melhor" (P30)
} 


\section{UNIDADE 4}

A unidade 4 procurou dar aos pais uma visão mais ampla, saindo do ambiente doméstico para a perspectiva da comunidade, legislação e recursos a serem utilizados para a educação da criança. Foram retomados alguns temas das unidades anteriores: aspectos da deficiência auditiva, diagnóstico, reabilitação e desenvolvimento da comunicação da criança. Também foi reforçada nesta última unidade, a importância das avaliações para acompanhar a evolução da criança e planejar novas intervenções, destacando-se que o resultado final do processo de reabilitação abrangia o esforço das pessoas envolvidas e as expectativas suas e da comunidade. Assim, pais e profissionais como médicos, fonoaudiólogos, terapeutas e professores, poderiam ajudar-se mutuamente e participar da construção de uma sociedade solidária e inclusiva de fato.

Os assuntos que foram abordados na unidade 4, em relação à continuidade do trabalho com a criança, traziam informações quanto às providências após o diagnóstico, tais como o tratamento que compreendia a reabilitação, a educação e envolvia tomada de decisões por parte dos pais.

Procurou-se esclarecer aos pais que reabilitação é o trabalho direcionado à comunicação e linguagem enquanto que ensino é voltado à escolarização, leitura e escrita, com a intenção que os pais percebessem a importância da opção deles ao priorizar uma forma de comunicação (oral ou gestual), escolher e colaborar com os profissionais. Assim estariam influenciando o desempenho atual e o futuro pretendido para a criança.

Foi sugerido na unidade que os pais elaborassem perguntas aos profissionais, de modo que, ao expressarem suas dúvidas a respeito da deficiência auditiva, refletissem sobre seu próprio conhecimento. Depois, com ênfase nas potencialidades e habilidades da criança, foi solicitado que informassem tarefas e atividades em que ela poderia ser bem sucedida, em casa, na escola, futuramente no trabalho e em outras oportunidades.

Foram apresentadas algumas informações sobre a escolarização, as abordagens educacionais, as escolhas que os pais devem fazer e como podem acompanhar o desempenho do filho e ajudar os professores, sendo solicitado que apontassem outros esclarecimentos que achavam necessários para melhor se relacionarem com a escola e com os professores.

Uma tarefa desta unidade junto à comunidade era que os pais visitassem uma escola, que poderia ser a do filho, e conversassem com professores ou diretores sobre a aceitação ou o motivo da não aceitação dos alunos com deficiência auditiva ou surdez. Os pais também deveriam verificar se estes frequentavam sala de aula comum ou especial e solicitar informações sobre a abordagem de comunicação utilizada, a disponibilidade de sala de recursos e a formação dos professores. Finalizando o tema da escola, pediu-se que os pais verificassem com os professores qual a maior dificuldade que enfrentavam. 
Quanto ao serviço de saúde da sua cidade, foram solicitadas aos pais informações sobre a vacinação contra rubéola e as providências dos profissionais quando percebiam problemas de audição nas crianças.

A última proposta da unidade 4 visava ampliar a percepção dos pais quanto à sua própria competência. Foi solicitado que conversassem com a família de uma criança com deficiência auditiva, sobre as dificuldades que enfrentavam, criando oportunidade de partilharem seus problemas, suas experiências e conhecimentos.

A análise dos questionários devolvidos mostrou que, quanto ao entendimento a esta unidade, 90,0\% (27) das respostas foram afirmativas e, 73,3\% (22) negativas quanto à dificuldade nas questões e atividades propostas. Das respostas que mencionavam dificuldade, 20,0\% (6) das justificativas eram a respeito das perguntas ou do conteúdo da unidade, que era extenso e um pouco difícil de entender e sobre a escola, que a criança não frequentava.

\subsection{Avaliação do programa pelos pais}

$\mathrm{Na}$ avaliação geral segundo as respostas aos questionários das quatro unidades do programa, 93,1\% foram afirmativas quanto ao entendimento. As negativas diziam respeito a algumas das questões colocadas nas unidades ou à comunicação da criança que comprometeu a execução das tarefas. Verifica-se, portanto, que o programa, elaborado a partir do levantamento de necessidades e da realidade das famílias estudadas, em concordância com o que sugerem Colnago (2000), Harisson e Roush (2001) e Motti e Pardo (2003), dentre outros autores, foi adequado à compreensão dos pais.

Os pais responderam que não encontraram dificuldades em $73,9 \%$ das respostas nas quatro unidades. As respostas que referiam dificuldades apontavam as atividades propostas, quanto ao resultado obtido, queixando-se da participação e da comunicação da criança. Entretanto, embora admitindo dificuldades, três pais acharam válidas as atividades, referindo que as crianças começaram a aprender, citando o quadro de tarefas, ou que eles começaram a ensinar de acordo com as orientações recebidas, no caso dos conceitos de quantidade, tempo, igual e diferente.

As respostas dos pais a respeito do que poderia ser acrescentado ao programa e sugestões foram analisadas em conjunto. Do total, 76,0\% manifestaram que o conteúdo estava ótimo, muito bom, bom, nada deveria ser acrescentado ou não tinham sugestões, com elogios e agradecimentos:

"... eu nunca tive nem metade de todas essa informação, por isso, não tenho nada a acrescentar só tô satisfeita com tudo que aprendi, quero saber muito mais" (P30)

Em 24,0\% das respostas foram identificadas contribuições dos pais, mencionando assuntos relacionados à deficiência auditiva, ao diagnóstico e às 
intervenções, e sugerindo mais informações sobre o Implante Coclear e a oralização da criança surda:

O período do diagnóstico, essencial para o resultado do tratamento da criança, foi lembrado pelos pais. Além de citarem a importância de um programa informativo para médicos e serviços básicos de saúde, para melhorar a atenção nessa área e ampliar o acesso às avaliações, solicitaram mais oportunidades para exporem suas experiências e relatarem as dificuldades enfrentadas.

“... se possível colocar experiências de outros pais, pois, na minha cidade não temos grupos ou conhecidos para trocar experiências..." (P03)

Dentre as respostas, uma mãe respondeu que o programa a alertou para a prevenção da surdez e o reconhecimento de que os pais precisam ser trabalhados e fortalecidos devido à culpa e à dificuldade de aceitação, que os impede de iniciar o tratamento da criança em tempo hábil.

A insegurança dos pais em relação à própria capacidade de ajudar o filho se fez presente em algumas respostas onde requeriam mais orientações sobre lidar com a criança: como se comunicar, ensinar sobre o aparelho, noções de abstrato, de tempo, impor limites, trabalhar a autoestima, e pediam mais brincadeiras $e$ exercícios.

A escola foi tema do maior número de respostas dos pais $(24,0 \%)$, manifestando interesse deles por mais informações a respeito de métodos de ensino, alfabetização, inclusão e, principalmente, formação do professor e material de orientação para os mesmos.

Contribuições relacionadas à apresentação do material do programa sugeriram opções de múltipla escolha nos questionários.

Em meio às respostas dos pais nas entrevistas finais, foram encontrados depoimentos e relatos de experiências da adaptação do filho surdo à comunidade, destacando-se alguns que referem assuntos tratados no programa, como a dificuldade de transmitir o sentido do abstrato, a necessidade da persistência diante dos lentos resultados, a questão da aceitação da criança pelas pessoas:

\footnotetext{
"O medo de não conseguir entender sentimento... tem direito de saber o que é música... faço um sinal e falo pra ela que parece carinho, mandei cheirar perfume... falei que parece..." (P02)

“... já tava cansada, que eu ia desistir... ela (a fono) foi conversando comigo. Tá tão difícil pra mim, mas eu tenho que lutar, o que eu posso fazer eu faço... pouco a pouco vou ter resultado" (P18)
}

\section{CONSIDERAÇõES FINAIS}

A reabilitação da criança deficiente auditiva é dependente das condutas dos pais frente à aceitação do diagnóstico, às decisões sobre o tratamento, à 
exploração dos recursos familiares e comunitários para a estimulação do desenvolvimento dela, bem como a colaboração com terapeutas e profissionais. Para que os pais tenham condições de entender e desempenhar os papéis de incentivadores do desenvolvimento da criança e parceiros dos profissionais, orientações adequadas são imprescindíveis.

A organização dessas orientações em programas deve levar em consideração as necessidades e interesses dos pais, além do contexto da família, o apoio de familiares e amigos, os recursos da comunidade e o acesso ao acompanhamento que a criança precisa.

Este trabalho teve por objetivo elaborar e avaliar um programa de orientação aos pais de crianças com deficiência auditiva de graus severo e profundo, com dois a seis anos de idade, de modo a atender tais recomendações, ou seja, respeitando a realidade de cada família.

As orientações que os especialistas de diferentes áreas transmitem aos pais durante o diagnóstico da deficiência auditiva, fundamentaram a elaboração das quatro unidades do programa, dentro de uma perspectiva interdisciplinar. As dificuldades e interesses dos pais, bem como o conhecimento sobre as avaliações do filho e acompanhamentos indicados, foram identificados e complementados pelas suas opiniões a respeito do desempenho e necessidades da criança, deles próprios e das famílias, orientando assim o planejamento do programa. A perspectiva ecológica foi observada nas tarefas sugeridas, estimulando os pais a buscarem recursos e informações nos diversos ambientes frequentados pela família e pela criança.

Os resultados encontrados no desenvolvimento da pesquisa comprovaram que os pais participaram do programa, receberam as informações que esperavam para os orientarem no dia a dia e sugestões de atividades que adequaram ao contexto familiar, para auxiliarem o desenvolvimento global da criança.

O programa foi elaborado para ser aplicado às famílias sem limitações de escolaridade e de acordo com a avaliação dos resultados, os conteúdos e as tarefas sugeridas não devem ser simplificados. Pelo contrário, alguns pais queriam mais e todos, de modo geral, no esforço de ler, compreender e realizar as tarefas, também exercitaram suas habilidades:

“... na minha opinião está tudo muito bem esclarecido ... cabe a cada pai responder corretamente" (P19)

Este trabalho, a partir das sugestões dos próprios pais, pode ser enriquecido com informações e atividades para fortalecer a autoestima deles, a fim de que tenham confiança no que já dominam e para que seus conhecimentos possam ser úteis também para outros pais. 


\section{REFERÊNCIAS}

BARDIN, L. Análise de conteúdo. 3. ed. Lisboa: Edições 70, 2004. 223p.

BEVILACQUA, M.C.; FORMIGONI, G.M.P. Audiologia educacional: uma opção terapêutica para a criança deficiente auditiva. Carapicuiba: Pró-Fono, 1997. 86p.

BRONFENBRENNER, U. A ecologia do desenvolvimento humano: experimentos naturais e planejados. Porto Alegre: Artes Médicas, 1996. 267p.

CHEROW, E.; DICKMAN, D.M. C.; EPSTEIN, S. Recursos de organizações para famílias de crianças portadoras de surdez ou perda auditiva. Clínicas Pediátricas da América do Norte, Rio de Janeiro, v.46, n.1, p.153-162, 1999.

COLNAGO, N.A.S. Orientação para pais de crianças com síndrome de Down: elaborando e testando um programa de intervenção. 2000. 158p. Tese (Doutorado em Psicologia) Faculdade de Filosofia, Ciências e Letras de Ribeirão Preto, Universidade de São Paulo, Ribeirão Preto, 2000.

HARRISSON, M.; ROUSH, J. Information for families with young deaf and hard of hearing children: reports from parents and pediatric audiologists. In: INTERNATIONAL CONFERENCE A SOUND FOUNDATION THROUGH EARLEY AMPLIFICATION, 2, 2001, Chicago. Proceedings. Chicago: Phonak, 2001. p. 233-250. Disponível em: <http:// ww w.audiologyonline.com/management/ uploads/articles / Phonak_2001proceedings_27_chapter20.pdf>. Acesso em: 27 ago. 2010.

HARRISON, K.M.P.; LODI, A.C.B.; MOURA, M.C. Escola e escolhas: processo educacional dos surdos. In: LOPES FILHO, O.C. (Ed.). Tratado de fonoaudiologia. São Paulo: Roca, 1997. p.359-400.

HOLZHEIM, D.C.P.M. et al. Família e fonoaudiologia: o aprendizado da escuta. In: LOPES FILHO, O.C. (Ed.). Tratado de fonoaudiologia. São Paulo: Roca, 1997. p.415-436.

MINAYO, M.C.S. (Org.). Pesquisa social: teoria, método e criatividade. Petrópolis: Vozes, 1999. MOTTI, T.F.G. A rotina de um centro de referência em deficiência auditiva: perspectiva de pais e profissionais. 2000. 216p. Dissertação (Mestrado em Educação Especial) - Centro de Educação e Ciências Humanas, Universidade Federal de São Carlos, São Carlos, 2000.

MOTTI, T.F.G.; PARDO, M.B.L. Atenção aos pais durante os procedimentos de diagnóstico e indicação do aparelho de amplificação sonora individual (AASI) em crianças. Distúrbios da Comunicação, São Paulo, v.15, n.1, p.151-162, 2003.

SIGOLO, S.R.R.L. Educação de crianças com atraso de desenvolvimento na perspectiva bioecológica de Bronfenbrenner. In: SIGOLO, S. R. R. L.; MANZOLI, L. P. (Org.). Educação especial face ao desenvolvimento e à inserção social. Araraquara: Cultura Acadêmica, 2002. p.11-39.

SJOBLAD, S. et al. Parents' reactions and recommendations after diagnosis and hearing aid fitting. American Journal of Audiology, Rockville, v.10, n.1, p.24-31, 2001.

STELLING, E. A relação da pessoa surda com sua família. Espaço, Rio de Janeiro, n.11, p.44-47, 1999.

TURATO, E.R. Tratado da metodologia da pesquisa clínico-qualitativa: construção teóricoepistemológica, discussão comparada e aplicação nas áreas da saúde e humanas. 2. ed. Petrópolis: Vozes, 2003. 685 p.

Recebido em: $24 / 03 / 2010$

Reformulado em: 08/09/2010

Aprovado em: 04/11/2010 